\title{
Current surgical management of anomalous aortic origin of a coronary artery
}

\author{
Edward Buratto, MBBS, PhD, ${ }^{\mathrm{a}, \mathrm{b}, \mathrm{c}}$ and Igor E. Konstantinov, MD, PhD, FRACS ${ }^{\mathrm{a}, \mathrm{b}, \mathrm{c}, \mathrm{d}}$
}

Determining the optimal management of patients with an anomalous aortic origin of a coronary artery (AAOCA) has posed a tremendous challenge to cardiologists and surgeons alike, as the exact prevalence is unknown and the risk of sudden death is uncertain. This has led to considerable debate regarding the optimal surgical management of these patients. ${ }^{1-4}$ An expert consensus guideline on surgical management of the AAOCA was published in $2017,{ }^{5}$ and a large volume of literature has been published in subsequent years in light of these guidelines. The purpose of this focused review is to highlight recent key publications on the topic, so that the large volume of literature can be effectively utilized by our readership.

\section{RISK STRATIFICATION}

A broad spectrum of anomalies is contained within the diagnosis of AAOCA, which may be divided into 2 groups: left coronary artery arising from the right sinus (AAOLCA) and right coronary artery arising from the left sinus (AAORCA). Further variations of the anatomy include retroaortic, prepulmonic, interarterial, intramural, and intraconal courses. The effect of these variations was investigated by Jagatheeswaran and colleagues, ${ }^{3}$ who reported 560 patients with AAOCA enrolled in the Congenital Heart Surgeons' Society (CHSS) database between 1998 and 2016. They demonstrated that AAORCA is more common than AAOLCA ( $74 \%$ vs $23 \%$ ), but, conversely, AAOLCA is more frequently associated with ischemia than AAORCA (38\% vs $10 \% ; P<.001)$. Additional anatomic features associated with ischemia in AAOLCA are interarterial course, intramural course, high orifice, and slit-like orifice. All patients who had ischemia with AAORCA had an intramural course, with a longer length of intramural course

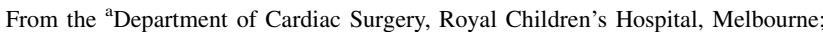
${ }^{b}$ Department of Paediatrics, University of Melbourne, Melbourne; ${ }^{c}$ Heart Research Group, Murdoch Children's Research Institute, Melbourne; and ${ }^{\mathrm{d} M e l b o u r n e ~ C h i l-~}$ dren's Centre for Cardiovascular Genomics and Regenerative Medicine, Melbourne, Australia.

Received for publication June 7, 2020; revisions received July 3, 2020; accepted for publication July 13, 2020; available ahead of print Sept 3, 2020.

Address for reprints: Igor E. Konstantinov, MD, PhD, FRACS, Royal Children's Hospital, Flemington Rd, Parkville, 3029, Australia (E-mail: igor.konstantinov@rch. org.au).

J Thorac Cardiovasc Surg 2021;161:206-12

0022-5223/ $\$ 36.00$

Crown Copyright (C) 2020 Published by Elsevier Inc. on behalf of The American Association for Thoracic Surgery

https://doi.org/10.1016/j.jtcvs.2020.07.118

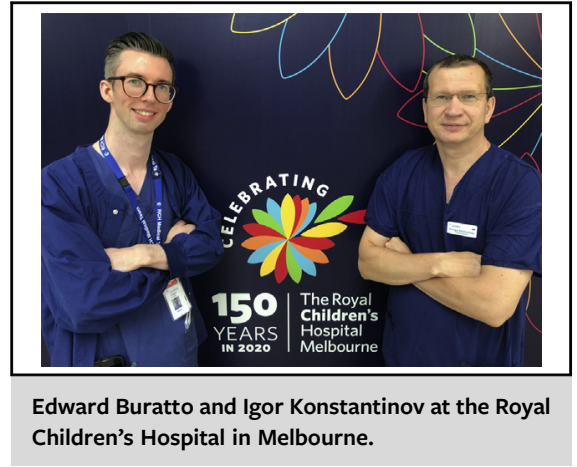

CENTRAL MESSAGE

Surgery for anomalous aortic coronary artery carries a low risk of mortality. However, there is a risk of aortic regurgitation and new ischemia, which must be considered when counseling patients.

associated with an increased risk of ischemia. ${ }^{3}$ Ischemia seems to be uncommon in patients with an intraconal, retroaortic, or prepulmonic course. ${ }^{3}$

Mery and colleagues ${ }^{4}$ used a decision analysis model to determine the relative benefit of surgery compared with observation in patients with AAOLCA and AAORCA over a range of ages. For patients with AAOLCA, surgery was the preferred strategy in patients age $<30$ years, whereas for older patients, observation resulted in equivalent or better outcomes than surgery. For patients with AAORCA, surgery was the preferred strategy only for patients age $<25$ years in whom the risk of sudden cardiac death was high and the risk of surgery was low.

\section{GUIDELINE RECOMMENDATIONS}

Balancing the risk of surgery with the risk of sudden cardiac death is challenging. Expert consensus guidelines from the American Association for Thoracic Surgery include the following key recommendation for surgical management ${ }^{5}$ : (1) patients with AAOCA and symptoms, syncope or aborted sudden cardiac death attributable to ischemia, 
should be offered surgery (class I); (2) asymptomatic patients with AAOLCA and an interarterial course should be offered surgery (class I); and (3) asymptomatic patients with AAORCA should be evaluated for inducible ischemia, and if asymptomatic and without ischemia, they may be observed and allowed to resume competitive athletics (class IIa).

\section{SURGICAL TECHNIQUES}

The multitude of surgical techniques for AAOCA repair is testament to the fact that the optimal surgical approach is currently elusive and the precise surgical strategy is yet to be defined. Superficially, it may appear that there is an array of competing, or even mutually exclusive, techniques for surgical correction of AAOCA. In fact, these techniques are complementary and revolve around the same anatomic principles (Figure 1). The ideal repair should emulate this normal anatomy, addressing potential mechanisms of ischemia, namely interarterial course, slit-like ostium, and abnormal ostial position. Such emulation might not be always achievable by unroofing alone and may require reimplantation or patch ostioplasty. Thus, currently described techniques should be considered as consecutive steps to achieving proper anatomic position of an adequately sized ostium. Although not all steps may be required in each patient to achieve the anatomic position of the ostium, failure to achieve such a natural position may result in new or persistent postoperative ischemia. ${ }^{3}$

Unroofing is the most widely used surgical technique for AAOCA, where intramural segment of the coronary artery (Figure 1, A) is unroofed with (Figure 1, B) or without detachment of the aortic valve commissure. The technique has been described in detail recently. ${ }^{6,7}$ Detachment of the aortic valve commissure may be performed intentionally to facilitate unroofing, or it may occur unintentionally when unroofing is performed above the commissure. Alternatively, the coronary may be unroofed above the commissure or partially unroofed in the correct sinus without taking down the commissure. Resuspension should be performed regardless of whether or not aortic valve commissural detachment was performed, as it is crucial to securely resuspend the commissure to prevent late aortic insufficiency. Yerebakan and colleagues ${ }^{8}$ recently reported that a modified unroofing technique with routine commissural resuspension was associated with a lower rate of aortic regurgitation (AR).

If the native anatomic position is not achieved after unroofing, then reimplantation may be required as a next step (Figure 1, $C$ and $D$ ). A detailed description of the technique was recently published by Carrel. ${ }^{9}$ A 90 -degree rotation of the button may be required to avoid kinking or tension. ${ }^{10,11}$ Alternatively, a patch ostioplasty (Figure 1,
$E-G)$ can be performed to create a new enlarged ostium as close to the native anatomic position as possible. ${ }^{1,11}$ This may be accompanied by translocation of the main pulmonary artery to reduce the risk of coronary compression of the interarterial segment when the coronary ostium has not been moved to its normal anatomic position. ${ }^{11}$

\section{OUTCOMES OF SURGERY}

Jegatheeswaran and colleagues ${ }^{12}$ reported the results of 395 patients from the CHSS database who underwent surgery for AAOCA between 2000 and 2018 at a median age of 13.3 years. Early mortality was $1 \%$. Freedom from coronary-related reoperation was $95 \%$ at 7 years. At 3 -year follow-up, freedom from mild or greater AR was $88 \%$ in patients without commissural manipulation, compared with $77 \%$ in those with commissural manipulation $(P=.05)$. Resolution of ischemia was achieved in $80 \%$ of patients, whereas $4 \%$ of patients had new-onset ischemia postoperatively. They concluded that although surgery for AAOCA is associated with low mortality and generally relieved ischemia, it is also associated with a significant risk of postoperative morbidity.

Fabozzo and colleagues ${ }^{13}$ reported 72 patients who underwent surgery for AAOCA between 1996 and 2014 at a median age of 8.5 years. Unroofing was performed in $89 \%$ of the patients, coronary reimplantation was performed in $11 \%$, and pulmonary artery translocation was performed in $1.4 \%$. There were no operative deaths. At a median follow- up of 4 years, 3 patients $(4.2 \%)$ had required reoperation, including 2 for $\mathrm{AR}$ and 1 for recurrent ischemia.

Sachdeva and colleagues ${ }^{14}$ reported the results of 63 patients who underwent unroofing for AAOCA between 1999 and 2015 at a median age of 13 years. There were no early deaths. At a median follow up of 3.1 years, 3 patients had experienced sudden cardiac arrest (including 1 death), and 1 patient had required aortic valve repair for severe AR. No patients had signs of reversible ischemia on follow-up testing.

Nees and colleagues ${ }^{15}$ reported 60 children who underwent surgery for AAOCA between 2001 and 2016 at a median age of 15.4 years. Unroofing was performed in $93 \%$, and reimplantation was performed in $7 \%$. There were no operative deaths. Postoperative echocardiography revealed new moderate or greater $\mathrm{AR}$ in $8 \%$ and new regional wall motion abnormality in $4 \%$. Reoperation was required in $5 \%$ of the patients at a median follow-up of 1.6 years. One patient required aortic valve replacement for moderate $\mathrm{AR}$, and 2 patients developed ostial coronary stenosis.

Mery and colleagues ${ }^{16}$ reported 44 children who underwent surgery for AAOCA between 2012 and 2017 at a median age of 14 years. The surgical technique was unroofing in 

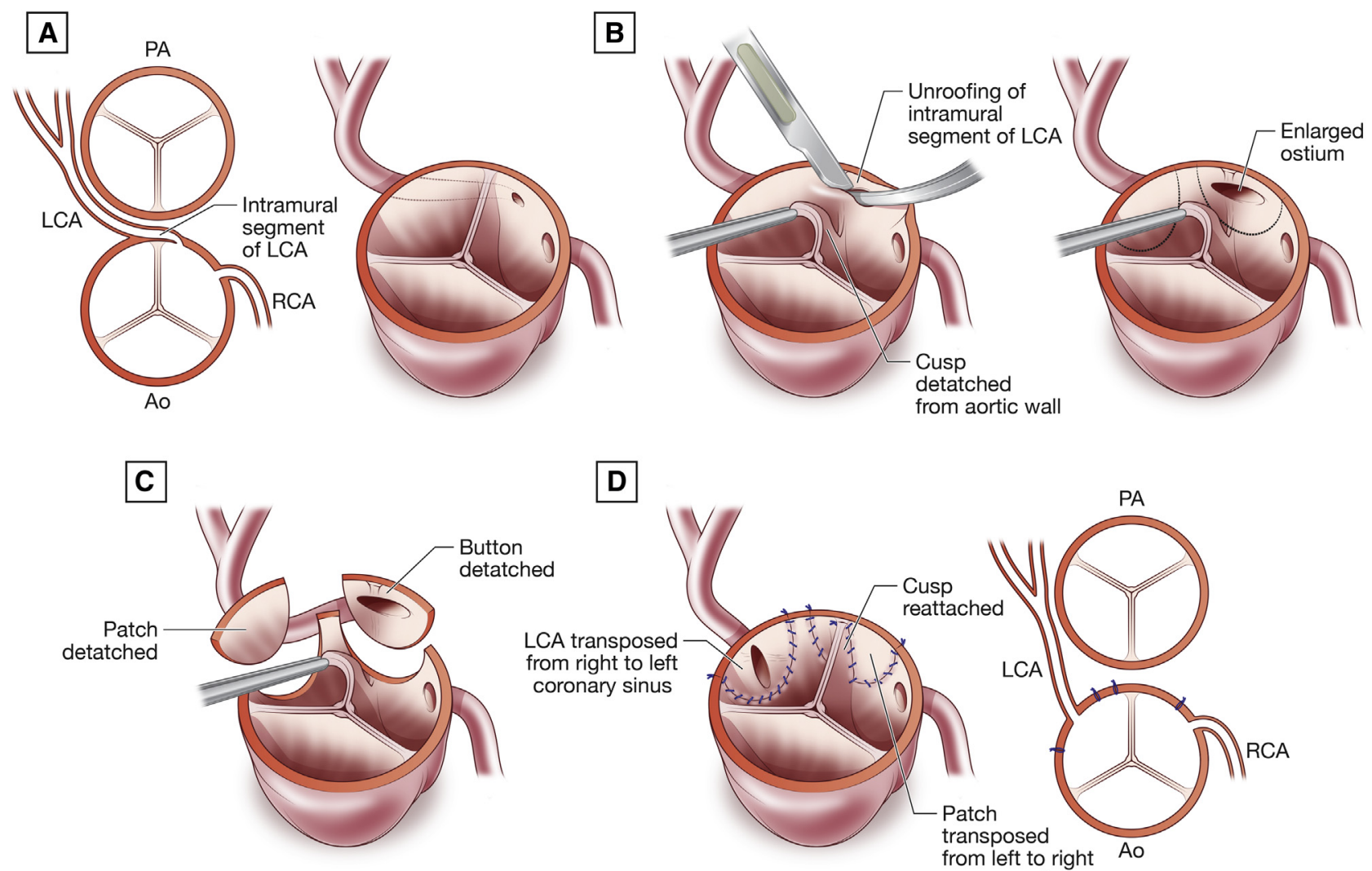

D
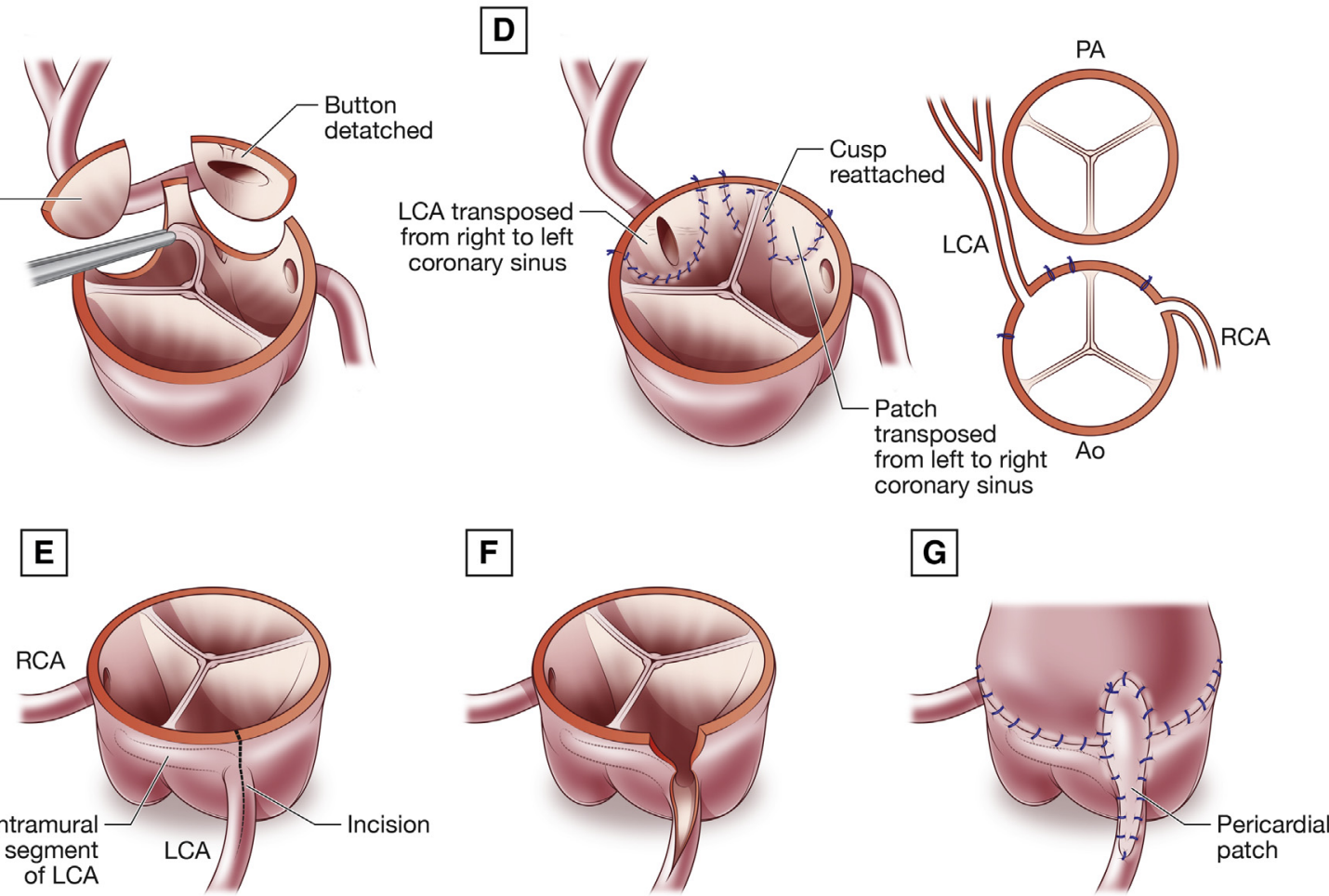

FIGURE 1. Anomalous origin of the left coronary artery. A, Schematic illustration of the anomalous left coronary artery with intramural interarterial course. The typical location of the intramural interatrial coronary segment is below the sinotubular junction. B, Commissural detachment may be performed to allow unroofing, or the commissure is left in situ and the coronary segment is unroofed above it. In either case, it appears crucial to resuspend the commissure securely to prevent aortic insufficiency. If unroofing of the coronary artery does not provide an adequate ostium in an anatomic position, it still could be compressed by the pulmonary artery. In such cases, detachment and mobilization of the coronary should be performed (C), and the coronary artery should be reimplanted into its anatomic position (D). Alternatively, the ostium can be incised (E and F) and patched (G) to allow a wide opening posteriorly to avoid coronary compression by the pulmonary artery. $P A$, Pulmonary artery; $L C A$, left coronary artery; $R C A$, right coronary artery; $A o$, aorta.

$80 \%$, reimplantation in $16 \%$, ostioplasty in $2 \%$, and side-side-anastomosis in $2 \%$. There were no operative deaths, and at a median follow-up of 3 years, $91 \%$ of the patients were asymptomatic and $95 \%$ had resumed physical activity.

From these studies, it is apparent that surgery for AAOCA carries a very low mortality. However, approximately $8 \%$ of patients will develop significant AR in the median term, and, perhaps even more importantly, approximately $4 \%$ of patients will develop new postoperative ischemia. Thus, these potential postoperative complication should be taken into account when offering surgery to asymptomatic patients. ${ }^{17}$ Despite the large amount of recent research on the topic, currently there are no uniform views on the etiologic issues and long-term outcomes of the various surgical strategies. 


\section{CONCLUSIONS}

The anatomic features associated with ischemia in AAOCA include AAOLCA with an intramural or interarterial course or a high or slit-like orifice and AAORCA with a long intramural segment. The greatest benefit for surgery is likely to be obtained by patients with ischemia and/or AAOLCA who are $<30$ years of age. Surgery is performed with low mortality; however, there is a risk of new AR and new ischemia postoperatively. Furthermore, up to one-fifth of patients have evidence of persistent ischemia. Based on current evidence and guidelines, it appears that surgery should be offered to patients with AAOLCA and AAORCA with symptoms or imaging evidence of ischemia, as well as to asymptomatic patients with an interarterial course of AAOLCA.

\section{Conflict of Interest Statement}

The authors reported no conflicts of interest.

The Journal policy requires editors and reviewers to disclose conflicts of interest and to decline handling or reviewing manuscripts for which they may have a conflict of interest. The editors and reviewers of this article have no conflicts of interest.

\section{References (The 10 best AATS papers on the topic are in bold type)}

1. Vouhé PR. Anomalous aortic origin of a coronary artery is always a surgical disease. Semin Thorac Cardiovasc Surg Pediatr Card Surg Annu. 2016;19: 25-9.

2. Mosca RS, Phoon CKL. Anomalous aortic origin of a coronary artery is not always a surgical disease. Semin Thorac Cardiovasc Surg Pediatr Card Surg Annu. 2016;19:30-6.

3. Jegatheeswaran A, Devlin PJ, McCrindle BW, Williams WG, Jacobs ML, Blackstone EH, et al. Features associated with myocardial ischemia in anomalous aortic origin of a coronary artery: a Congenital Heart Surgeons' Society study. J Thorac Cardiovasc Surg. 2019;158:822-34.e3.

4. Mery CM, Lopez KN, Molossi S, Sexson-Tejtel SK, Krishnamurthy R, McKenzie ED, et al. Decision analysis to define the optimal management of athletes with anomalous aortic origin of a coronary artery. J Thorac Cardiovasc Surg. 2016;152:1366-75.e7.

5. Brothers JA, Frommelt MA, Jaquiss RDB, Myerburg RJ, Fraser CD Jr, Tweddell JS. Expert consensus guidelines: anomalous aortic origin of a coronary artery. J Thorac Cardiovasc Surg. 2017;153:1440-57.

6. Schubert SA, Kron IL. Surgical unroofing for anomalous aortic origin of coronary arteries. Oper Tech Thorac Cardiovasc Surg. 2016;21:162-77.

7. Kotani Y, Sano S, Kasahara S. Repair of intramural coronary artery in anomalous aortic origin of a coronary artery. Oper Tech Thorac Cardiovasc Surg. 2018;23:40-8.

8. Yerebakan C, Ozturk M, Mota L, Sinha L, Gordish-Dressman H, Jonas R, et al. Complete unroofing of the intramural coronary artery for anomalous aortic origin of a coronary artery: the role of commissural resuspension? J Thorac Cardiovasc Surg. 2019;158:208-17.e2.

9. Carrel T. Surgical treatment of anomalous aortic origin of coronary arteries: the reimplantation technique and its modifications. Oper Tech Thorac Cardiovasc Surg. 2016;21:178-201.

10. Jadhav M, Pflaumer A, Naimo PS, Konstantinov IE. Anomalous aortic origin of the left coronary artery from the right coronary sinus: diagnosis and surgical repair of intramural retrovalvular coronary artery. Ann Thorac Surg. 2015;100: 2357-9.

11. Karl TR. Coronary artery from the wrong sinus of Valsalva: a physiologic repair strategy. Oper Tech Thorac Cardiovasc Surg. 2008;13:35-9.

12. Jegatheeswaran A, Devlin PJ, Williams WG, Brothers JA, Jacobs ML, DeCampli WM, et al. Outcomes after anomalous aortic origin of a coronary artery repair: a Congenital Heart Surgeons' Society study. J Thorac Cardiovasc Surg. 2020;160:757-71.e5.

13. Fabozzo A, DiOrio M, Newburger JW, Powell AJ, Liu H, Fynn-Thompson F, et al. Anomalous aortic origin of coronary arteries: a single-center experience. Semin Thorac Cardiovasc Surg. 2016;28:791-800.

14. Sachdeva S, Frommelt MA, Mitchell ME, Tweddell JS, Frommelt PC. Surgical unroofing of intramural anomalous aortic origin of a coronary artery in pediatric patients: single-center perspective. J Thorac Cardiovasc Surg. 2018; $155: 1760-8$.

15. Nees SN, Flyer JN, Chelliah A, Dayton JD, Touchette L, Kalfa D, et al. Patients with anomalous aortic origin of the coronary artery remain at risk after surgical repair. J Thorac Cardiovasc Surg. 2018;155:2554-64.e3.

16. Mery CM, De León LE, Molossi S, Sexson-Tejtel SK, Agrawal H, Krishnamurthy $\mathbf{R}$, et al. Outcomes of surgical intervention for anomalous aortic origin of a coronary artery: a large contemporary prospective cohort study. J Thorac Cardiovasc Surg. 2018;155:305-19.e4.

17. Naimo PS, Buratto E, Konstantinov IE. Commentary: surgery for an anomalous aortic origin of a coronary artery: to do, or not to do? That is the question. $J$ Thorac Cardiovasc Surg. 2020;160:772-3.

Key Words: anomalous coronary, coronary unroofing, coronary transfer 


\section{Management of AAOC Artery: Recent articles from AATS Journals}
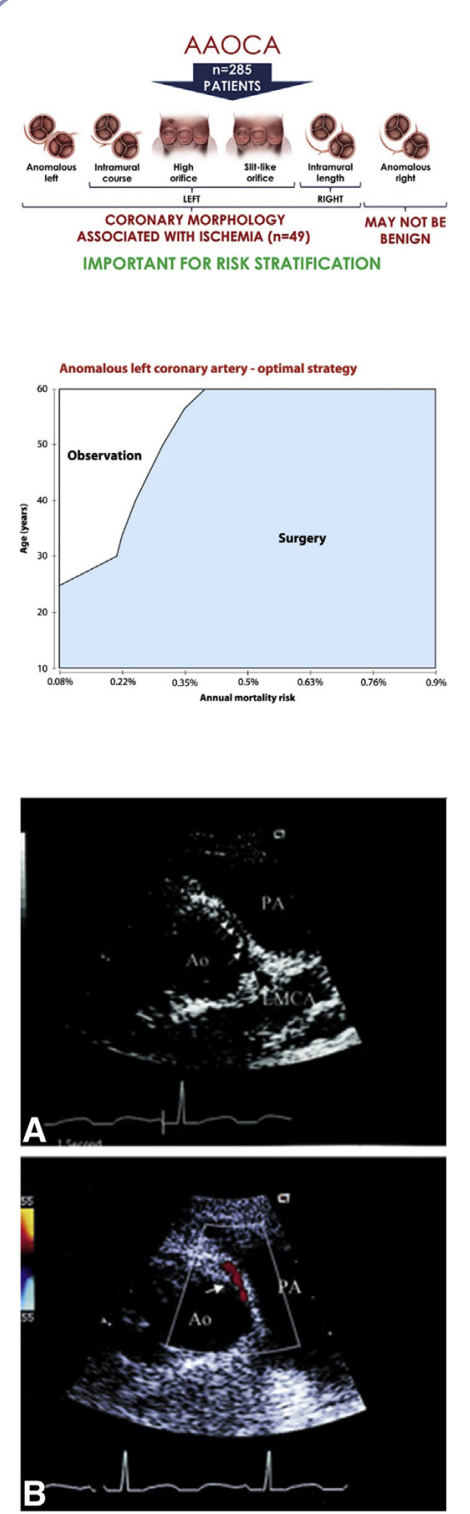

JTCVS: Features associated with myocardial ischemia in anomalous aortic origin of a coronary artery: A Congenital Heart Surgeons' Society study. Jegatheeswaran A, Devlin P, McCrindle BW, Williams WG, Blackstone, Jacobs ML, DeCampli WM, Caldarone CA, Gaynor JW, Kirklin JK, Lorber RO, Mery CM, St. Louis JD, Silvana M, Brothers JA. J Thorac Cardiovasc Surg. 2019;158(3):822-834.E3.

Commentary: The devil you know and the devil you don't. Sen DG, Kimball TR. J Thorac Cardiovasc Surg. 2019;158(3):835-836.

JTCVS: Decision analysis to define the optimal management of athletes with anomalous aortic origin of a coronary artery. Mery CM, Lopez KN, Molossi S, Sexson-Tejtel SK, Krishnamurthy R, McKenzie ED, Fraser CD Jr, Cantor SB. J Thorac Cardiovasc Surg. 2016; 152(5):1366-1375.E7.

Commentary: Tackling a complex problem via a novel approach: Decision analysis may improve quality of life for patients with anomalous aortic origin of a coronary artery. Wilder T, Williams WG. J Thorac Cardiovasc Surg. 2016;152(5):1376-1377.

JTCVS: Expert consensus guidelines: Anomalous aortic origin of a coronary artery. Brothers JA, Frommelt MA, Jaquiss RDB, Myerburg RJ, Fraser CD Jr, Tweddell JS. J Thorac Cardiovasc Surg. 2017;135(6):1440-1457.

Commentary: Guidelines should bother us, not comfort us. DeCampli WM. J Thorac Cardiovasc Surg. 2017;153(6):1458-1461.

Commentary: Anomalous aortic origin of a coronary artery: The gaps and the guidelines. Jacobs ML. J Thorac Cardiovasc Surg. 2017;135(6):1462-1465. 


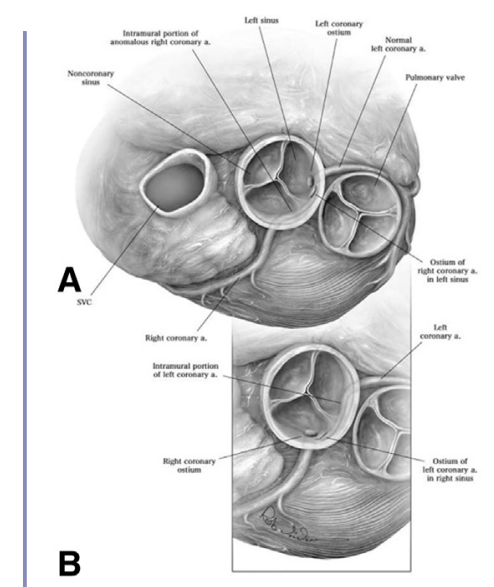

OPTECHS: Surgical unroofing for anomalous aortic origin of coronary arteries. Schubert SA, Kron IL. Oper Tech Thorac Cardiovasc Surg. 2016;21(3):162-177.

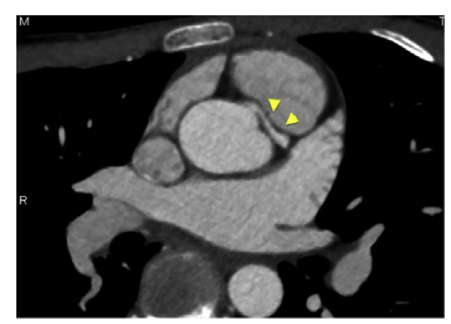

OPTECHS: Repair of intramural coronary artery in anomalous aortic origin of a coronary artery. Kotani Y, Sano S, Kasahara S. Oper Tech Thorac Cardiovasc Surg. 2018;23:40-48.

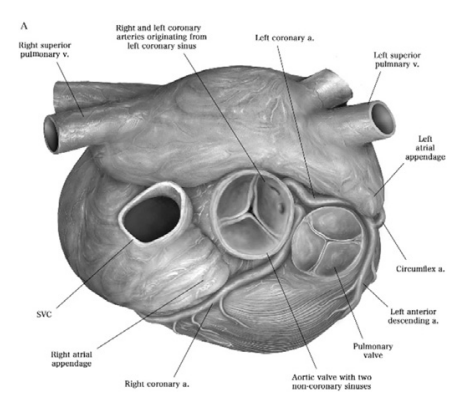

OPTECHS: Surgical treatment of anomalous aortic origin of coronary arteries: The reimplantation technique and its modifications. Carrel T. Oper Tech Thorac Cardiovasc Surg. 2017;21:178-201.

Complications after AAOCA surgery

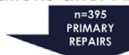

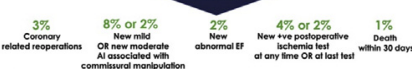

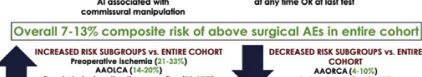

JTCVS: Outcomes following anomalous aortic origin of a coronary artery repair: A Congenital Heart Surgeons' Society study. Jegatheeswaran A, Devlin PJ, Williams WG, Brothers JA, Jacobs ML, DeCampli WM, Fleishman CE, Kirklin JK, Mertens L, Mery CM, Molossi S, Caldarone CA, Aghaei N, Lorber RO, McCrindle BW. J Thorac Cardiovasc Surg. 2020 [In press].

Commentary: I guess I'm just confused... isn't this information sobering? Fraser CD Jr. J Thorac Cardiovasc Surg. 2020 [In press].

Commentary: No free lunch: What we talk about when we talk about anomalous aortic origin of a coronary artery. Chen JM. J Thorac Cardiovasc Surg. 2020 [In press].

Commentary: Surgery for an anomalous aortic origin of a coronary artery: To do, or not to do? That is the question. Naimo PS, Buratto E, Konstantinov IE. J Thorac Cardiovasc Surg. 2020 [In press]. 

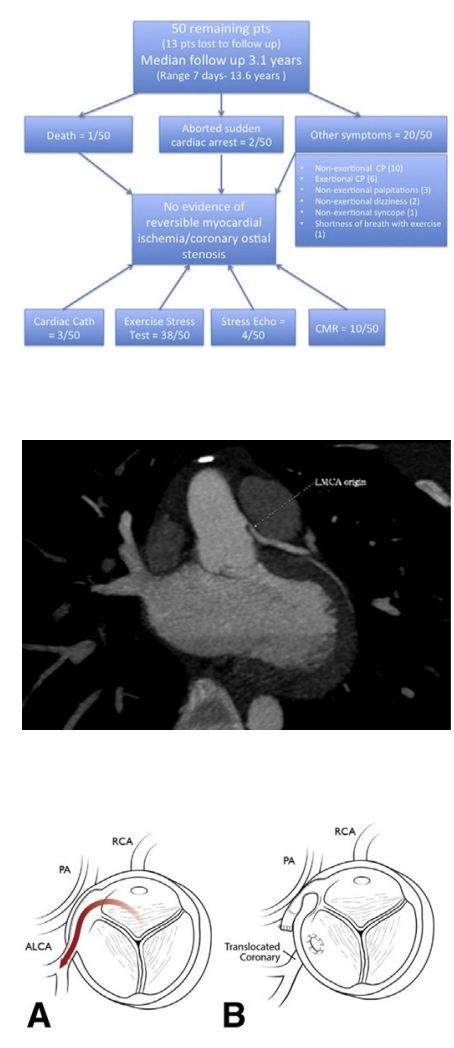

JTCVS: Surgical unroofing of intramural anomalous aortic origin of a coronary artery in pediatric patients: Single-center perspective. Sachdeva S, Frommelt MA, Mitchell ME, Tweddell JS, Frommelt PC. J Thorac Cardiovasc Surg. 2018;155(4):1760-1768.

Commentary: Primum non nocere when the treatment is worse than the disease. Jaggers J. J Thorac Cardiovasc Surg. 2018;155(4):1769-1770.

Commentary: The search for the Holy Grail: Risk stratification in anomalous aortic origin of a coronary artery. Molossi S, Mery CM. J Thorac Cardiovasc Surg. 2018;155(4):17581759.

JTCVS: Patients with anomalous aortic origin of the coronary artery remain at risk after surgical repair. Nees SN, Flyer JN, Chelliah A, Dayton JD, Touchette L, Kalfa D, Chai PJ, Bacha EA, Anderson BR. J Thorac Cardiovasc Surg. 2018;155(6):2554-2564.

Commentary: QED? Not yet! Yerebakan C. J Thorac Cardiovasc Surg. 2018;155(6):2565-2566.

JTCVS: Outcomes of surgical intervention for anomalous aortic origin of a coronary artery: A large contemporary prospective cohort study. Mery CM, De León LE, Molossi S, Sexson-Tejtel SK, Agrawal H, Krishnamurthy R, Masand P, Qureshi AM, McKenzie ED, Fraser CD Jr. J Thorac Cardiovasc Surg. 2018;155(1):305-319.E4.

Commentary: "Cui periculum"-Who is at risk? Mainwaring RD. $J$ Thorac Cardiovasc Surg. 2018;155(1):322-324.

Commentary: Anomalous aortic origin of a coronary artery: $90 \%$ of optimal therapy is 50\% improved technology. Mosca RS. J Thorac Cardiovasc Surg. 2018;155(1):320-321.

Commentary: Gathering evidence on rare diseases: Anomalous aortic origin of a coronary artery. Jacobs ML. J Thorac Cardiovasc Surg. 2018;155(1):303-304. 